\title{
A streamlined method for the extraction of outer membrane vesicles (OMVs) from Bordetella pertussis
}

\author{
Sekhavati $\mathbf{M}^{1}$, Siadat $\mathrm{SD}^{2}$, Noofeli $\mathbf{M}^{3}$, Mohebati Mobarez $\mathrm{A}^{1^{*}}$ \\ ${ }^{1}$ Department of Bacteriology, Faculty of Medical Sciences, Tarbiat Modares University, Tehran, Iran. \\ ${ }^{2}$ Microbiology Research Center (MRC) Pasteur Institute of Iran, Tehran, Iran. \\ ${ }^{3}$ Human Bacterial Vaccine Department, Razi Vaccine and Serum Research Institute, Agricultural Research, Education and \\ Extension Organization (AREEO), Karaj, Iran.
}

\begin{abstract}
Introduction: In spite of high vaccination coverage, whooping cough (pertussis) is still a worldwide health problem. The main reason for pertussis outbreak is waning immunity of safer acellular vaccines which have replaced the more reactogenic cellular vaccines. A new generation of pertussis vaccines that is potent and safe is desperately needed to control the disease. Previous studies have indicated that outer membrane vesicles (OMVs) obtained from Bordetella pertussis have desirable characteristics which make them a good candidate for application as pertussis vaccine. They contain surface immunogens in a native structure, are self-adjuvant and are easily uptaken by the antigen presenting cells. Methods: B. pertussis Tohama strain was cultured at $35^{\circ} \mathrm{C}$ in Stainer-Scholte broth. The OMVs were isolated by a new sequential ultracentrifugation method. The extracted OMVs were characterized by electron microscopy, SDSPAGE and ELISA assays. Results: The existence of pertussis toxin, filamentous haemagglutinin and a 69-kDa antigen in B. pertussis OMVs was verified using an ELISA assay. Electron microscopy showed the size of these OMV's at 40$200 \mathrm{~nm}$. The ELISA results indicated that the OMVs extracted using this protocol contain major immunogens. Conclusion: We report for the first time a simple protocol for the efficient extraction of $B$. pertussis OMVs. This protocol can be used in the process of making new generations of $B$. pertussis vaccines.
\end{abstract}

KEYWORDS: Bordetella pertussis, outer membrane vesicles, extraction, characterization, vaccine.

\section{INTRODUCTION}

Pertussis (also known as whooping cough) is a contagious respiratory illness that is particularly dangerous in infants. The causative agent of pertussis is the fastidious, Gram-negative bacterium Bordetella pertussis [1]. Pertussis is highly contagious and is preventable by vaccination. Despite massive vaccination programs over more than 60 years, this disease has remained a major global concern and one of the most lifethreatening childhood diseases [2, 3]. The original sources of pertussis for infants are the family members [4-6]. The transmission is almost always directly from person to person [7]. The first generation of pertussis vaccines were inactivated and alum-adjuvanted which were developed in 1940s-50s with a good efficacy which are still in use in many countries $[8,9]$. According to the WHO, from 1999 to 2014, pertussis vaccinations reduced infants death by around 100,000 cases

*Corresponding Author: Ashraf Mohabati Mobarez, Department of Bacteriology, Faculty of Medical Sciences, Tarbiat Modares University, Tehran, Iran

Email: mmmobarez @ modares.ac.ir

Tel/Fax: (+98) 2182883862
[10]. There is, however, a growing concern about the safety of the whole-cell vaccination (wP) and its side-effects that has led to its replacement by the safe acellular vaccines (aP), containing immunogenic antigens of B. pertussis [11, 12].

The shift from more reactogenic wP to aP decreased vaccine side-effects, however, it led to several outbreaks and resurgence of pertussis $[13,14]$. The causes of these outbreaks were low efficacy and short immunity duration induced by aP vaccines $[15,16]$. Moreover, aP vaccines with alum as adjuvant induce mainly Th2 (humoral) response that contributes to reduced protection, while Th1/Th17 (cellular) response induced after wP priming leads to the lung clearance, long lasting immunity and protection $[17,18]$.

Outer membrane vesicles (OMVs) are spherical nanoparticles (10-300 $\mathrm{nm}$ in diameter) released from Gram-negative bacteria. These nano-spheres are principally composed of lipopolysaccharides (LPS), outer membrane proteins (OMPs) and periplasmic proteins [19-21]. OMVs have been identified as good vaccine candidates for bacterial infections [22]. The OMVs of B. pertussis contain several major immunogens that can be used as a new and potent acellular pertussis vaccine with 
low reactogenicity [23-26]. Here, a new extraction method of B. pertussis OMVs is introduced.

\section{MATERIALS and METHODS}

\section{Strains and growth conditions}

B. pertussis Tohama phase I strain was used in this study. A 10 $\mu 1$ aliquot of the stock bacterium was grown on Bordet-Gengou (BG) agar plate and incubated for 3-5 days at $35^{\circ} \mathrm{C}$. A few small colonies were sub-cultured on Stainer-Scholte (SS) liquid medium for large-scale production of the cultures [27].

\section{Isolation of OMVs}

After approximately $48 \mathrm{~h}$ of incubation (decelerating growth phase), the culture sample was centrifuged at $10,000 \times \mathrm{g}$ for 30 min at $4{ }^{\circ} \mathrm{C}$. The supernatant was discarded and the pellet was incubated at $56^{\circ} \mathrm{C}$ oven for $30 \mathrm{~min}$, then washed twice with phosphate buffer saline (PBS) and centrifuged at 7,000 $\times \mathrm{g}$ for $10 \mathrm{~min}$. The pellet was dissolved in sodium chloride buffer and homogenized by pipetting several times to make a uniform suspension. Then the suspension was incubated at room temperature for $45 \mathrm{~min}$, after which $0.1 \mathrm{M}$ Tris- $\mathrm{HCl}, \mathrm{pH}: 8$ and $10 \mathrm{mM}$ EDTA was added (8 times weight of the suspension) and homogenized by shaking for $15 \mathrm{~min}$. The suspension was then treated with $0.1 \mathrm{M}$ Tris- $\mathrm{HCl}, \mathrm{pH}: 7.5,10 \mathrm{mM}$ EDTA and $10 \% \mathrm{~W} / \mathrm{V}$ sodium deoxycholate (up to $5 \%$ of the suspension) and mixed for $5 \mathrm{~min}$, then centrifuged at $17,000 \times \mathrm{g}$ for $1 \mathrm{~h}$. The supernatant was separated carefully in a new tube and treated with $100 \mu \mathrm{l}$ of $0.1 \mathrm{M}$ Tris-HCl, pH: 7.5, $10 \mathrm{mM}$ EDTA and 5\% W/V sodium deoxycholate. Finally, the supernatant was pelleted at $60,000 \times \mathrm{g}$ for $4 \mathrm{~h}$ at $4^{\circ} \mathrm{C}$. The pellet was then dissolved in $5 \mathrm{ml}$ of $3 \%$ sucrose and filtered through $0.2 \mu \mathrm{m}$ filter (Milipore, Germany). The filtered sample containing OMVs was stored at $4^{\circ} \mathrm{C}$.

\section{Transmission electron microscopy (TEM)}

The extracted OMVs were suspended in $0.1 \mathrm{M}$ ammonium acetate ( $\mathrm{pH}:$ 7). A 5- $\mu 1$ aliquot was drop-cast on a coppercoated grid. After evaporation of the liquid, the grid was stained with phosphotungstic acid and examined with a Zeiss EM10c TEM (Germany).

\section{Protein assay}

The concentration of total protein in OMVs was measured using the Bradford method with bovine serum albumin as standard [28].

\section{Protein profile of OMVs}

For the separation of proteins in OMVs, SDS-PAGE analysis was performed. The extracted OMVs $(5 \mu \mathrm{g})$ were resuspended in laemmli sample buffer [29] and incubated at $95^{\circ} \mathrm{C}$ for 15 min. Electrophoresis was done at $22^{\circ} \mathrm{C}$ and constant voltage. After electrophoresis, the separated proteins were stained by Coomassie Blue R-250. OMVs from B. pertussis (Tahoma) were extracted 20 times with the method explained above. In all repeats, the size and SDS-PAGE profiles were determined.

\section{ELISA}

To evaluate the presence of specific pertussis antigens such as pertussis toxin (PT), filamentous haemagglutinin (FHA), and 69-kDa antigen, direct ELISA was carried out with standard antigens (NIBSC) and OMV- hyperimmune serum as antibody. First, hyperimmune serum with OMVs was produced as antigen and complete/incomplete Freund's adjuvant, according to the methods previously published [30]. Briefly, $40 \mu \mathrm{l}$ of OMVs (50 $\mu \mathrm{g}$ total protein) was mixed with $40 \mu \mathrm{l}$ of complete Freund's adjuvant and injected subcutaneously to $8 \mathrm{BALB} / \mathrm{c}$ mice at the time zero after homogenization. In addition, 2 booster immunizations were carried out at 2 and 4 weeks after the priming immunization with $40 \mu \mathrm{l}$ incomplete Freund's adjuvant and $40 \mu \mathrm{l} \mathrm{OMVs}(50 \mu \mathrm{g}$ total protein) per dose. After 14 days and bleeding from heart, serum samples were collected as hyperimmune serum. A checkerboard titration was carried out to determine the optimum antigen concentration. Antigen concentrations considered in the study included $150 \mathrm{ng} / \mathrm{well}$ for $\mathrm{PT}$ and FHA, and $40 \mathrm{ng} /$ well for $69-\mathrm{kDa}$ protein that were coated on 96-well ELISA plates, and incubated overnight at $4^{\circ} \mathrm{C}$. The plate was then washed once with PBS and blocked with $150 \mu \mathrm{l} /$ well of $3 \%$ skimmed milk (Sigma, Germany) and incubated for $24 \mathrm{~h}$ at $4^{\circ} \mathrm{C}$. After thorough washing, $50 \mu \mathrm{l}$ of hyperimmune serum (1:100 in $3 \%$ skimmed milk) was added and the mixture was incubated at $37^{\circ} \mathrm{C}$ for $2 \mathrm{~h}$. As a negative control, few wells were coated with BSA $(10 \mu \mathrm{g} / \mathrm{ml})$. Each serum sample was tested in duplicate. The wells were washed 4 times and anti-mouse IgG HRP-conjugated (Sigma USA), diluted at 1:40,000, was added at $50 \mu \mathrm{Ll} /$ well and the samples were incubated at $37^{\circ} \mathrm{C}$ for $2 \mathrm{~h}$. The wells were then washed four times to remove unbound antibodies. The plate was incubated with $100 \mu \mathrm{l}$ of 363', 5'5'-tettamethyl benzidine (TMB) at room temperature in dark. The reaction was stopped after $20 \mathrm{~min}$ by adding $25 \mu \mathrm{l}$ stop solution ( $\mathrm{HCl} \mathrm{5.8 \% )}$ and the absorbance was measured at $450 \mathrm{~nm}$ using an ELISA plate reader (STAT FAX, USA).

Specificity test

To perform the specificity test, the hyperimmune serum, normal mouse serum (NMS), diphtheria, tetanus serum (DT) and Pasteurella serum (PAS) were used. Three dilutions (1:100, $1: 200,1: 400)$ were prepared from each sample. The serums were put in two separate plates and their optical density was measured. Only one dilution (1/100) was used for NMS.

\section{RESULTS}

\section{OMVs isolation and characterization}

The OMVs were extracted from B. pertussis Tohama cells according to the procedure described. For evaluation of the shapes and size, the extracted OMVs were examined with an electron microscope after negative phosphotungstate potassium staining (Fig. 1A). The size was determined to be 40-200 nm and topographical shapes were intact in 10 extraction examined via TEM. The protein profiles of extracted OMVs were studied by SDS-PAGE (Fig. 1B) and the results matched with that measured by the Bradford method [28] was $120 \mu \mathrm{g} / \mathrm{ml}$.

\section{ELISA}

The assessment of antibody development pattern proved that all the extracted OMVs had specific pertussis antigens (PT, FHA, 69-kDa) as determined by ELISA (Fig. 2). The sera from the normal mouse serum (NMS) did not develop titer as confirmed by ELISA (Fig. 2). The results of specificity test are presented in the Table 1 . The increase in the absorbance value was only observed in the pooled sample in all 3 dilutions whilst the other samples did not show any raise. The results of the specificity test thus showed that anti-PT, anti-FHA and anti-69-kDa were highly specific with no cross reaction.

\section{Specificity test}

The increase in the absorbance value was only observed in the hyperimmune serum sample in all 3 dilutions whilst other samples did not reveal any increase. Therefore, anti-PT, antiFHA and anti-69-kDa were completely specific and there was no cross reaction with other antigens (Table1). 


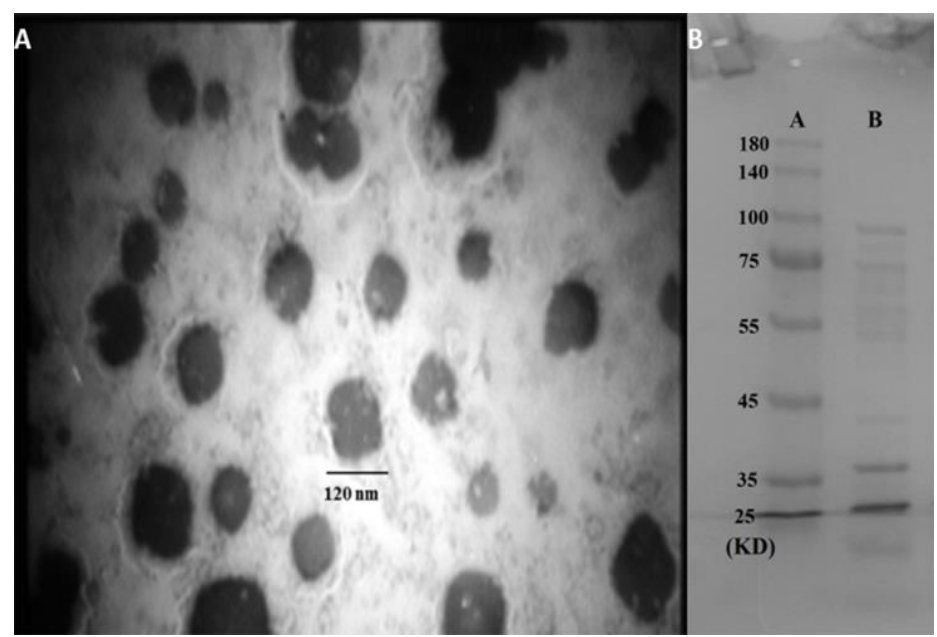

Fig. 1. Characterization of Bordetella pertussis Tohama strain phase I OMVs: (A), TEM image of negative stained OMVs extracted from $B$. pertussis Tohama. (B), SDS-PAGE $12.5 \%(\mathrm{w} / \mathrm{v})$ of the extracted OMVs. Lane A shows the Mw marker and lane B shows the protein profile of the obtained OMVs.

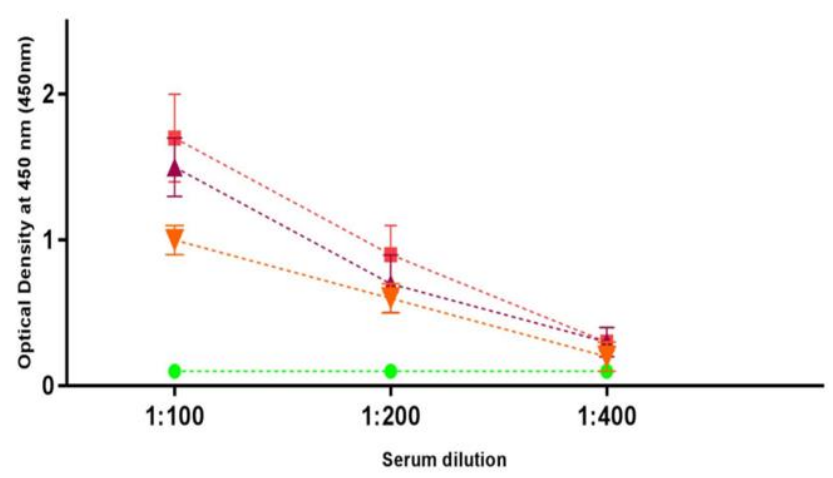

^. FHA $\because 69-\mathrm{kDa} \backsim \mathrm{PT} \bullet \mathrm{NMS}$

Fig. 2. Antibody levels in the hyperimmune serum and NMS against PT, FHA and 69-kDa

Table. 1. Optical density values of the hyperimmune serum, anti-DT and anti-PAS as antibodies and PT, FHA and 69-kDa as antigens in ELISA assay.

\begin{tabular}{|c|c|c|c|c|c|c|c|}
\hline \multirow[b]{2}{*}{ Sample name } & \multirow[b]{2}{*}{ Serum dilution } & \multicolumn{2}{|c|}{ PT } & \multicolumn{2}{|c|}{ FHA } & \multicolumn{2}{|c|}{ 69-kDa } \\
\hline & & $\begin{array}{c}\mathbf{A}^{450} \\
\text { (plate1) }\end{array}$ & $\begin{array}{c}\mathbf{A}^{450} \\
\text { (plate2) }\end{array}$ & $\begin{array}{c}\mathbf{A}^{450} \\
\text { (plate1) }\end{array}$ & $\begin{array}{c}\mathrm{A}^{450} \\
\text { (plate2) }\end{array}$ & $\begin{array}{c}\mathbf{A}^{450} \\
\text { (plate1) }\end{array}$ & $\begin{array}{c}\mathbf{A}^{450} \\
\text { (plate2) }\end{array}$ \\
\hline \multirow{3}{*}{ Hyperimmune serum } & $1: 100$ & 1.852 & 1.801 & 1.636 & 1.702 & 1.091 & 1.126 \\
\hline & $1: 200$ & 0.951 & 0.892 & 0.821 & 0.810 & 0.721 & 0.788 \\
\hline & $1: 400$ & 0.562 & 0.502 & 0.522 & 0.501 & 0.412 & 0.458 \\
\hline \multirow{3}{*}{ DT } & $1: 100$ & 0.187 & 0.175 & 0.187 & 0.175 & 0.187 & 0.175 \\
\hline & $1: 200$ & 0.144 & 0.151 & 0.144 & 0.151 & 0.144 & 0.151 \\
\hline & $1: 400$ & 0.088 & 0.060 & 0.088 & 0.060 & 0.088 & 0.060 \\
\hline \multirow{3}{*}{ PAS } & $1: 100$ & 0.236 & 0.211 & 0.236 & 0.211 & 0.236 & 0.211 \\
\hline & $1: 200$ & 0.221 & 0.289 & 0.221 & 0.289 & 0.221 & 0.289 \\
\hline & $1: 400$ & 0.085 & 0.032 & 0.085 & 0.032 & 0.085 & 0.032 \\
\hline NMS & $1: 100$ & 0.152 & 0.121 & 0.152 & 0.121 & 0.152 & 0.121 \\
\hline
\end{tabular}

\section{DISCUSSION}

In this study we presented a novel procedure for the isolation of pertussis OMVs from Tohama strain. The extracted OMVs contain important immunogens (PT, FHA and 69-kDa) that could elicit host immune responses and could also be used to develop a new generation of efficient aP vaccine. The OMVs contain not only main immunogens but also LPS that can play the role of an adjuvant [31-33].

Our protocol of pertussis OMVs extraction includes a series of simple steps with high yields. In other studies, ultracentrifugation at $100,000 \times \mathrm{g}$ has been used for the isolation of pertussis OMVs. However, an ultracentrifuge is not a commonly available item in many laboratories. Therefore, an alternative method with lower speed of centrifugation will be more useful. In this study we used $60,000 \times \mathrm{g}$ for the isolation of OMVs. Unless otherwise specified by regulatory agencies, in aP vaccine production, there is no need for the purification of obtained OMVs and the isolated OMVs can be directly used as a vaccine candidate.

The extracted OMVs were nano-particle vesicles with the diameters ranging between $40-200 \mathrm{~nm}$ (Fig. 1A) that is consistent with other reports of OMVs extracted from other $B$. pertussis strains [24, 26, 34]. This size range also suggests that the nano-spheres can be readily uptaken by the antigen presenting cells [35]. The protein profiles of the extracted
OMVs studied by SDS-PAGE showed several proteins that based on their molecular weights appear to be main immunogens, as confirmed by ELISA assay. At least 20 repetitions of OMVs extraction were performed. The similarity in morphology, size and presence of immunogens were observed in all cases. It is envisaged that the presented protocol may pave the way for an easier and more efficient extraction of OMVs for the future vaccine studies against pertussis.

\section{ACKNOWLEDGEMENT}

This work was supported by Tarbiat Modares University and Razi Vaccine \& Serum Research Institute, Iran. We thank Seyed Reza Banihashemi (Director of of Immunology Department of Razi Institute) for allowing the access to the laboratory facilities.

\section{CONFLICT OF INTEREST}

The authors declare that they have no conflict of interest.

\section{REFERENCES}

1. Bottero D, Gaillard ME, Zurita E, Moreno G, Martinez DS, Bartel E, et al. Characterization of the immune response induced by pertussis OMVsbased vaccine. Vaccine. 2016;34(28):3303-9 
2. Liu L, Johnson HL, Cousens S, Perin J, Scott S, Lawn J, et al. Child Health Epidemiology Reference Group of WHO and UNICEF Global, regional, and national causes of child mortality: an updated systematic analysis for 2010 with time trends since 2000. Lancet. 2012;379(9832):2151-61.

3. Chiappini E, Stival A, Galli L, De Martino M. Pertussis re-emergence in the post-vaccination era. BMC infectious diseases. 2013;13(1):151.

4. Jardine A, Conaty SJ, Lowbridge C, Staff M, Vally H. Who Gives Pertussis to Infants?: Source of Infection for Laboratory Confirmed Cases Less than 12 Months of Age During an Epidemic, Sydney, 2009. Communicable diseases intelligence quarterly report. 2010;34(2):116.

5. Wendelboe AM, Hudgens MG, Poole C, Van Rie A. Estimating the role of casual contact from the community in transmission of Bordetella pertussis to young infants. Emerging themes in epidemiology. 2007;4(1):15. 6. Skoff TH, Kenyon C, Cocoros N, Liko J, Miller L, Kudish K, et al. Sources of infant pertussis infection in the United States. Pediatrics. 2015:peds. 2015-1120.

7. Trainor EA, Nicholson TL, Merkel TJ. Bordetella pertussis transmission. Pathogens and disease. 2015;73(8).

8. Jefferson T, Rudin M, DiPietrantonj C. Systematic review of the effects of pertussis vaccines in children. Vaccine. 2003;21(17):12.

9. Amirthalingam G, Gupta S, Campbell H. Pertussis immunisation and control in England and Wales, 1957 to 2012: a historical review. Euro Surveill. 2013;18(38):20587.

10. Yeung KHT, Duclos P, Nelson EAS, Hutubessy RCW. An update of the global burden of pertussis in children younger than 5 years: a modelling study. The Lancet Infectious Diseases. 2017;17(9):974-80.

11. Burdin N, Handy LK, Plotkin SA. What is wrong with pertussis vaccine immunity? The problem of waning effectiveness of pertussis vaccines. Cold Spring Harbor perspectives in biology. 2017:a029454.

12. Sato Y, Sato H. Development of acellular pertussis vaccines. Biologicals. 1999;27(2):61-9.

13. Cherry JD. Why do pertussis vaccines fail? Pediatrics. 2012;129(5):968-70

14. Clark TA. Changing pertussis epidemiology: everything old is new again. Journal of Infectious Diseases. 2014;209(7):978-81

15. Gasperini G, Biagini M, Arato V, Gianfaldoni C, Vadi A, Norais N, et al. Outer Membrane Vesicles (OMV)-based and proteomics-driven antigen selection identifies novel factors contributing to Bordetella pertussis adhesion to epithelial cells. Molecular \& Cellular Proteomics. 2017:mcp. RA117. 000045.

16. Gaillard ME, Bottero D, Moreno G, Rumbo M, Hozbor D. Strategies and new developments to control pertussis, an actual health problem. Pathogens and disease. 2015;73(8):1-5.

17. Diavatopoulos DA, Edwards KM. What is wrong with pertussis vaccine immunity? Why immunological memory to pertussis is failing. Cold Spring Harbor perspectives in biology. 2017:a029553.

18. Ross PJ, Sutton CE, Higgins S, Allen AC, Walsh K, Misiak A, et al. Relative contribution of Th1 and Th17 cells in adaptive immunity to Bordetella pertussis: towards the rational design of an improved acellular pertussis vaccine. PLoS Pathog. 2013;9(4):e1003264

19. Kulp A, Kuehn MJ. Biological functions and biogenesis of secreted bacterial outer membrane vesicles. Annual review of microbiology. 2010;64:163-84.
20. Kulkarni HM, Jagannadham MV. Biogenesis and multifaceted roles of outer membrane vesicles from Gram-negative bacteria. Microbiology. 2014;160(10):2109-21.

21. Lee EY, Choi DS, Kim KP, Gho YS. Proteomics in gram-negative bacterial outer membrane vesicles. Mass spectrometry reviews. 2008;27(6):535-55.

22. Roier S, Zingl FG, Cakar F, Durakovic S, Kohl P, Eichmann TO, et al A novel mechanism for the biogenesis of outer membrane vesicles in Gramnegative bacteria. Nat Commun. 2016 Jan 25;7:10515. PubMed PMID 26806181. Pubmed Central PMCID: PMC4737802. Epub 2016/01/26. eng.

23. Bitto NJ, Kaparakis-Liaskos M. The Therapeutic Benefit of Bacterial Membrane Vesicles. International journal of molecular sciences. 2017;18(6):1287.

24. Asensio CJA, Gaillard ME, Moreno G, Bottero D, Zurita E, Rumbo M, et al. Outer membrane vesicles obtained from Bordetella pertussis Tohama expressing the lipid A deacylase PagL as a novel acellular vaccine candidate. Vaccine. 2011;29(8):1649-56.

25. Gaillard ME, Bottero D, Errea A, Ormazábal M, Zurita ME, Moreno G, et al. Acellular pertussis vaccine based on outer membrane vesicles capable of conferring both long-lasting immunity and protection against different strain genotypes. Vaccine. 2014;32(8):931-7.

26. Roberts R, Moreno G, Bottero D, Gaillard ME, Fingermann M, Graieb A, et al. Outer membrane vesicles as acellular vaccine against pertussis. Vaccine. 2008;26(36):4639-46

27. Bottero D, Gaillard M, Errea A, Moreno G, Zurita E, Pianciola L, et al. Outer membrane vesicles derived from Bordetella parapertussis as an acellular vaccine against Bordetella parapertussis and Bordetella pertussis infection. Vaccine. 2013;31(45):5262-8.

28. Bradford MM. A rapid and sensitive method for the quantitation of microgram quantities of protein utilizing the principle of protein-dye binding. Analytical biochemistry. 1976;72(1-2):248-54

29. Laemmli UK. Cleavage of structural proteins during the assembly of the head of bacteriophage T4. nature. 1970;227(5259):680.

30. Coligan JE, Bierer BE, Margulies DH, Shevach EM, Strober W. Short protocols in immunology: a compendium of methods from current protocols in immunology2005.

31. Moshiri A, Dashtbani-Roozbehani A, Najar Peerayeh S, Davar Siadat S. Outer membrane vesicle: a macromolecule with multifunctional activity. Human vaccines \& immunotherapeutics. 2012;8(7):953-5.

32. Hegerle N, Paris A-S, Brun D, Dore G, Njamkepo E, Guillot S, et al. Evolution of French Bordetella pertussis and Bordetella parapertussis isolates: increase of Bordetellae not expressing pertactin. Clinical Microbiology and Infection. 2012;18(9):E340-E6.

33. Bouchez V, Brun D, Cantinelli T, Dore G, Njamkepo E, Guiso N. First report and detailed characterization of $\mathrm{B}$. pertussis isolates not expressing pertussis toxin or pertactin. Vaccine. 2009;27(43):6034-41.

34. Hozbor D, Rodriguez M, Fernandez J, Lagares A, Guiso N, Yantorno O. Release of outer membrane vesicles from Bordetella pertussis. Current microbiology. 1999;38(5):273-8.

35. O'Hagan DT, MacKichan ML, Singh M. Recent developments in adjuvants for vaccines against infectious diseases. Biomolecular engineering. 2001;18(3):69-85. 